PRZEGLĄD RUSYCYSTYCZNY 2020, nr 3(171)

DOI 10.31261/pr.7870

FILIPPO CAMAGNI

Uniwersytet Jagielloński

(D ORCID: http://orcid.org/oooo-0oo1-8908-5642

\title{
ЭСХАТОЛОГИЧЕСКИЙ ХАРАКТЕР ПАМЯТИ В ПРОЗЕ ВЛАДИМИРА ШАРОВА
}

\section{THE ESCHATOLOGICAL NATURE OF MEMORY \\ IN THE PROSE OF VLADIMIR SHAROV}

The purpose of the article is to analyze the category of memory in some of Vladimir Sharov's most famous novels, such as: The Rehearsals (1992), Before and During (1992), The Old Girl (1998), Raising Lazarus (2002) and Be Like Children (2008). As it turns out, Sharov describes a reality in which, through the transmission of personal memories, crystallized into text and passed from generations to generations throughout eternity, can extend life of the individuum to the point of practical immortality. From a paper diary, containing all the smallest details from somebody's life experience in chronological order, to the interrogation protocols, which are stored in the archives of the NKVD: text becomes in Sharov's novels the most important repository of memory, through which it becomes possible not only to «resurrect», but also to relive everything anew. Therefore it can be noticed the prominence of the eschatological component in Sharov's works: memory can be identified with immortality, and oblivion with death.

Keywords: memory, immortality, Sharov, myth, text

В статье Непредсказуемая реальность Владимира Шарова петербургский критик Александр Беззубцев-Кондаков, предлагая собственную трактовку опубликованных до 2010 г. романов Владимира Шарова ${ }^{1}$, замечает, что творчество современного русского прозаика напоминает «вечные круги повторяющихся,

1 Владимир Александрович Шаров (1952-2018) - один из самых значимых русских современных прозаиков, поэт, эссеист, кандидат исторических наук. В 2014 г. награждён премией «Русский Букер» за роман Возвращение в Ezunem. 
закольцованных вопросов, сюжетов и идей ${ }^{2}$, а чтение его романов - «движение по кругу» ${ }^{3}$. Действительно, читателю шаровских произведений кажется, что он постоянно возвращается «к исходной точке» - к похожим между собой тезисам, к сходным образам и сюжетным пластам, к ряду тематически созвучных вопросов. Среди них особенно выделяется вопрос человеческой памяти: едва ли не все герои Шарова задумываются над её значением, пытаются установить её физические пределы, а также изучают природу, механизмы и функции воспоминаний.

В настоящей статье мы постараемся выявить специфику человеческой памяти и систематизировать её многообразные проявления, изображенные в произведениях Репетиции (1992), До и во время (1992), Старая девочка (1998), Воскрешение Лазаря (2002) и Будъте как дети (2008). Следует уточнить, что цель этой работы не проследить эволюцию авторского отношения к вопросу памяти в хронологической перспективе (что в случае романов Владимира Шарова, который на протяжении тридцати лет литературного творчества прибегал к тем же повествовательным приёмам и идеям, представлялось бы менее целесообразным), а, скорее, сфокусировать внимание на эстетических и тематических составляющих, на основе которых сформулировать общий для всех вышеупомянутых источников вывод о значении категории памяти.

Современный научный подход к изучению механизмов человеческой памяти выделяет четыре процесса, взаимосвязанных друг с другом: запоминание (запечатление новой информации посредством её кодирования в виде «следов памяти»), сохранение (краткосрочное или долговременное удержание в памяти накопленной информации), воспроизведение (возобновление, актуализация в сознании приобретённого опыта) и забывание 4 . Стержневым для героев Шарова оказывается именно процесс сохранения. Это не только отражается на композиции шаровских произведений (составленных чаще всего в виде дневнико-

2 А. Беззубцев-Кондаков, Непредсказуемая реальность Владимира Шарова, «Северная Аврора» 2010, № 11, http://reading-hall.ru/publication.php?id=3704 (23.08.2019).

3 Там же.

4 А. Бондар, Психология памяти. Учебное пособие для бакалавриата и магистратуры, ред. А. Касатов, Издательство Уральского университета, Екатеринбург 2018, с. 50. 
вых записей, писем или копий протоколов допросов), но и на концептуальном уровне: сохранение в материальной форме письменных сведений о человеке исключает возможности его «исчезновения» из социального пространства и обеспечивает ему своего рода вечную жизнь 5 . Связь памяти и бессмертия вовсе не случайна: по мнению шаровских героев, главная функция памяти заключается именно в возможности межпоколенной передачи личных воспоминаний и подробностей из жизни предков посредством их увековечения в письменной форме 6 . Об этом свидетельствуют попытки героев Шарова организовывать, упорядочивать и «запечатлевать» как можно больше деталей из прошлого.

Поскольку человеческая память не способна удержать всю накопленную в течение жизни информацию, нужен дополнительный носитель, позволяющий существенно расширить её объём за пределы мозговых тканей. По мнению рассказчика из романа Воскрешение Лазаря, впервые опубликованного в 2002 г. в «Знамени», каждый человек является живым хранилищем собственного жизненного опыта: в памяти одного из героев повести, театроведа Александра Петровича Грубера, знавшего и помнившего всё о театре, заключено множество подробно-

5 В книге Памяти памяти русский прозаик и поэт Мария Степанова воспринимает неизбежность смерти и окончательного забвения как «несправедливое» событие, с которым сердце не склонно мириться. Согласно писательнице, каждый человек живёт с надеждой на то, что где-то существует «другая, мудрая память, способная удерживать в горсти всё и всех, бывших и ещё не бывших». Однако по мнению Степановой, глаголы спасти и сохранить «значат одно и то же» только в потусторонней перспективе, вне которой всякие попытки овеществить память с помощью технологического «мусора» становятся лишь формой «условного, ограниченного бессмертия», трюком, благодаря которому «полное и окончательное исчезновение каждого из нас можно [...] припорошить обманками, дающими ощущение присутствия». Ср.: М. Степанова, Памяти памяти. Романс, Новое издательство, Москва 2018, с. 77-78.

6 Бумага, хрупкий хранитель информации, в романах Шарова противопоставлена разрушительной силой огня, который уничтожает бумажные свидетельства о прошлом и приводит к их забвению. В романе Возвращение в Ezunem символично изображен пожар в одном из московских народных архивов. Для того, чтобы как-то возместить потерю таких ценных воспоминаний и восстановить по крайней мере частицу прошлого, заведующие архива «[...] берут всё, что принесёшь, никому не отказывают» (см.: В. Шаров, Возвращение в Ezuпет, Издательство АСТ: Редакция Елены Шубиной, Москва 2015, с. 25). 
стей и анекдотов из жизни актёров, режиссёров, а также детали из спектаклей, их декораций. Поэтому смерть Грубера, утверждает рассказчик Воскрешения Лазаря, «станет смертью целой вселенной»7. Повествователь задумывается над тем, сколько воспоминаний ушло бы с ним, если бы историк театра не записал их: «[...] вот Грубера не станет и вместе с ним сразу же умрут сотни актёров со всеми их ролями и сотни постановок с режиссёрскими находками, декорациями, светом, потому что он последний из живых, кто это видел и помнит» ${ }^{8}$. Одним словом, вместе с Грубером исчезнет, утратится навсегда всё то, что не было каким-то образом «материально» зафиксировано. Рассказчик из Воскрешения Лазаря продолжает: «Меня тогда поразило, сколько людей от него зависит, сколько человек, наверное, сейчас молятся, чтобы он не умирал, жил и вот, как сейчас нам, рассказывал» ${ }^{9}$.

Несмотря на то, что спасение всего человечества при помощи письменных свидетельств является задачей, переходящей границы разумного, рассказчик Воскрешения Лазаря решает привести свой семейный архив в порядок ${ }^{10}-$ селится в особняке рядом с кладбищем, на котором похоронен его отец, и начинает работать в кладбищенском архиве, где сохраняются письма его родителя: «У меня есть обязательства перед людьми, у которых взяты их бумаги. Никто другой здесь не справится, все нити в моей голове, по дурости я не составил ни легенды, ни настоящего путеводителя [...] Большинства людей, о которых я говорю, нет в живых. Это - о них последняя память. Если я не приведу архив в порядок, он сгодится разве что на растопку» ${ }^{11}$. Итак, повествователь, в некотором соответствии с «философией общего дела» Николая Фёдорова ${ }^{12}$, начинает процесс восстановления

7 И. Ащеулова, Проблема поиска, сохранения и реализации ценностей как проблема связи поколений в романе В. Шарова «Воскрешение Лазаря» // Русская литература в ХХ веке: имена, проблемы, культурный диалог, вып. 9: «Отцы» $u$ «дети» в русской литературе $X X$ века, Томск 2008, c. 210.

8 В. Шаров, Воскрешение Лазаря, Вагриус, Москва 2003, с. 19-20.

9 Там же, с. 20.

10 Мария Степанова тоже считает упорядочивание семейного архива своего рода «спасательной операцией», уберегающей тексты от неактуальности и забвения. Ср.: М. Степанова, Памяти памяти. Романс..., с. 24.

${ }_{11}$ Там же, с. 298.

12 Аллюзии и непосредственные комментарии к тезисам отца русского космизма можно выявить едва ли не во всех произведениях Владимира Шарова. По 
в памяти (то есть, «воскрешения») не только отца, но и всех тех, кто принадлежал к его культурной среде. Владимир Шаров таким образом подчёркивает власть, преимущество текста как источника знания о действительности. Только то, что записано, обеспечивает устойчивость исторической памяти, преемственность которой не зависит от социокультурных процессов, происходящих на уровне общества в целом, а является «приватным делом», обусловленным лишь созданием и передачей частных письменных свидетельств о прошлом.

В романе До и во время, впервые опубликованном в «Новом мире» в 1992 г., Синодик опальных (написанный в конце XVI века по указанию царя Ивана Грозного с целью поминовения лиц, пострадавших в годы его правления) вводится в качестве примера письменного хранилища, в котором навсегда запечатлены следы памяти. Именно с такой целью Алёша, один из главных героев повести, намерен за стенами психиатрической больницы составить свой собственный Синодик опальных - для того, чтобы «оплакивать» - в переносном смысле - тех людей, которые, пишет Алёша, «ушли раньше времени, как говорят, до срока, и от которых ничего не осталось, кроме моей памяти. А когда уйду я, не останется и её» ${ }^{13}$. Проект Алёши воскресить тех, которые, умирая, «чувствовали себя обделёнными, опальными и обманутыми жизнью» ${ }^{14}$, в первую очередь и его сопалатников, основан на его желании остановить «ту беду», которая непременно придет к каждому, кто лежит рядом с ним в той же больничной палате - то есть, грядущую потерю памяти.

На фоне этой сюжетной канвы выделяется и другой мотив, непосредственно отсылающий к тематике памяти и бессмертия - мотив забвения. В произведениях Шарова традиционная оппозиция памяти/забвения проблематизируется в эсхатологической перспективе - она семантически тождественна противопоставлению понятий «сохранение» и «уничтожение»,

мнению одного из персонажей в Воскрешении Лазаря, например, спасение русского народа обусловлено именно физическим воскрешением умерших, что приведёт к обретению «рая на Земле»: поэтому сыновей следует переселить на кладбища, создать там школы, музеи и библиотеки, затем собрать все материальные «следы», все свидетельства об умерших предках, «чтобы помочь сынам воскресить отцов» (с. 82).

${ }_{13}$ В. Шаров, До и во время, ArsisBooks, Москва 2009, с. 18.

${ }^{14}$ Там же. 
«бессмертие» и «смерть». Семантическое тождество забвения и смерти у Шарова постоянно актуализируется. Если в Воскрешении Лазаря утверждается равносильный характер беспамятства и смерти (то есть, полного исчезновения личности), то в романе До и во время способность запоминать у тех, кто перенёс инсульт, сопровождающийся внезапными потерями сознания и нарушением расстройства воспоминаний, сравнивается на метафорическом уровне с трагической историей одной семьи во время войны:

Часть их [больных] мозга, очевидно, и сейчас была здорова, но она не могла пробиться сквозь больные ткани, восстановить связи, найти своих, так бывает во время войны: семью раскидало по стране, кто на фронте, и неизвестно, жив ли, погиб, а может быть, ранен и лежит в госпитале или пропал без вести, и про остальных тоже ничего не известно: бомбёжки, эвакуация, все для всех канули, и никто никого не может разыскать. Никто не знает, есть ли у него ещё жена, дети или он на этом свете один и всё ни к чему ${ }^{15}$.

Как заметил петербургский исследователь Иван Шейко-Маленьких, «пространство прозы Шарова подвержено всеобщей амнезии, с которой герои борются теми или иными способами [...] Беспамятство героев Шарова заставляет их рассказывать один сюжет снова и снова, занимаясь бесконечным редактированием своей и чужой истории, все варианты которой оказываются равноправны» ${ }^{16}$.

В романе До и во время Алёша тоже страдает хронической болезнью, которая вызывает неотвратимую потерю памяти. Герой осознаёт в полной мере безнадёжность своего положения: вместе с постепенным снижением познавательной способности, он начинает терять и восприятие времени. Опять актуализируется семантическое сопоставление между понятиями «забвение» и «смерть»: «Память сделалась центром моего мира, я терял её так мгновенно, что это больше всего походило на смерть» ${ }^{17}$. Однако, герой находит утешение в мысли, что, не будучи уже привязанным к устойчивым временным координатам, он получит возможность «вернуться назад».

15 Там же, с. 115.

${ }^{16}$ И. Шейко-Маленьких, Проблемы поэтики прозы Владимира Шарова, «Известия РГПУ им. А. И. Герцена» 2006, № 19, с. 86.

${ }^{17}$ В. Шаров, До и во время..., с. 13. 
Возвращение к прошлому ${ }^{18}$ с целью восстановления утраченных воспоминаний для многих героев Владимира Шарова обусловлено не только ведением, но и чтением дневника. Художественный образ бумажного дневника (вместо фотоальбомов или других мультимедийных средств) возникает практически во всех произведениях Шарова в качестве важнейшего хранилища личных воспоминаний. Синодик опальных Алёши становится его дневником: герой записывает и, следовательно, увековечивает навсегда воспоминания из своего детства и истории пациентов психбольницы. Они сами обращаются к Алёше, избавителю, с просьбой включить их в новый Синодик опальных: тогда «люди здесь, где смерть была делом естественным, где она была ежедневна, желанна, считалась благословением, перестали умирать. Они как бы отдались мне в руки. Стараясь ничем не помешать, никак не отвлечь, они день за днём тихо и кротко лежали на своих койках, но я видел, что каждый из них верит, надеется, что именно его я выберу, чтобы сохранить» ${ }^{19}$. Закрепление собственного жизненного опыта на бумаге, таким образом, служит залогом посмертного существования человека: «В общем, это понятно», размышляет другой герой из повести До и во время: «[...] всё, что не попало в дневник, было записано у мамы в голове, и она знала, что, если забудет, всё как бы умрет или даже вообще не рождалось $[. ..] »^{20}$.

Полезным для нашего исследования является и пример Веры Николаевной Радостиной, главной героини повести Старая девочка (впервые опубликованной в 1998 г.) $)^{21}$. В дневнике Веры описана в мельчайших деталях её повседневная жизнь на протяжении 20-х и 30-х годов. Вера записывает всё, не щадит подробностей даже о своих любовных приключениях, в том числе с товарищем Сталиным, по отношению к которому проявляет

18 «Возвращение» на образном уровне играет значимую роль в художественном неомифе Владимира Шарова. Оно использовано то ли в сопоставлении с обратным движением (как в романе Возвращение в Eгипет, в котором автор сначала изображает исход евреев из Египта в Землю Обетованную, затем - потерю веры в Бога и метафорическое возвращение избранного народа в Египет), то ли в качестве постепенного восстановления памяти о прошлом.

${ }^{19}$ В. Шаров, До и во время..., с. 107.

${ }^{20}$ Там же, с. 35.

${ }^{21}$ Прототип Веры Радостиной появился уже в романе До и во время. В этой повести героиня записывает историю любви с двоюродным дедом рассказчика для того, чтобы остался навсегда след их чувств. 
исключительную преданность и верность. Первые сомнения относительно советского режима возникают у героини после внезапного ареста и расстрела мужа: именно от неумения высказать свою обиду и мириться с настоящим, зарождается желание «вернуться назад», к прошлому. С целью восстановления прошлого Вера начинает перечитывать свои мемуарные очерки, чтобы заново пережить, пусть в обратном порядке, собственную жизнь. Действительно, героиня обходит законы линейного времени и начинает физически молодеть.

В романе Старая девочка загадочная судьба Веры Радостиной переплетается с общей историей Советского Союза и служит для автора фоном, на котором возможно сформулировать свою собственную интерпретацию советской мифологии. Если каждый историк творит миф (который, по словам Николая Бердяева, является не вымыслом, а «реальностью иного порядка»), то с полным основанием можно считать Владимира Шарова, кандидата исторических наук, «мифотворцем» ${ }^{22}$.

Например, в романе Старая девочка оказывается, что советские органы считают дневники Веры серьёзной опасностью для успешного исхода революции, поскольку история «старой девочки», которая постепенно, день за днём, возвращается назад к дореволюционному прошлому, может служить вредным примером и для других советских граждан, находящихся в похожем положении. Для народного комиссара внутренних дел Николая Ежова освежение воспоминаний о светлом прошлом является самым серьёзным оружием антипропаганды, способным в будущей перспективе даже свергнуть советскую власть. «Два варианта», заявляет Ежов после переговоров со Сталиным: «Первый арестовать Веру и немедленно её ликвидировать. Однако, если нас это не устраивает, Клейман просит санкции на изъятие её дневников ${ }^{23}$. Ведь без дневников возвращение к истокам и восстановление утраченных воспоминаний невозможно: недаром Ежов считает, что

память человека слаба, без дневника Вера рано или поздно начнёт путаться, дни у нее смешаются, она то будет идти назад, то снова вперед и изза этого станет сердиться на себя, раздражаться. Станет говорить, что сама себя обманула. В конце концов, совсем заплутавшись, бросит свою причуду.

${ }_{22}^{2}$ А. Беззубцев-Кондаков, Непредсказуемая реальность Владимира Шарова.... ${ }^{23}$ В. Шаров, Старая девочка, Наш дом - L’Age d'Homme, Москва 2009, с. 37. 
Тогда и другие, посмотрев на нее, подвёл итог Ежов, этот путь тоже не выберут ${ }^{24}$.

Предлагая весьма неожиданную образную модель советского миропорядка, Владимир Шаров «шокирует читателя и непредсказуемостью, провокационностью сюжета, и парадоксальной философией, и вольным толкованием религиозных догматов, и фантастическим взглядом на историю России, и кочующей из романа в роман „навязчивой” темой воскрешения мертвых» ${ }^{25}$. На страницах своих произведений Шаров постоянно выстраивает и перестраивает свой авторский «неомиф» ${ }^{26}$, в основе которого лежит весьма оригинальное эсхатологическое толкование доктрины большевизма. Приверженцы коммунизма имели только одну цель - обретение бессмертия и, следовательно, воплощение божьего рая на Земле. Само собой разумеется, в этом проекте важную роль играло учение Николая Фёдорова (как заметил Беззубцев-Кондаков, «эсхатология Федорова [...] «вскормила» большевизм. В трактовке Шарова выходит, что и Ленин в немалой степени был последователем Фёдорова [...]»²7). Действительно, в романе До и во время так звучит монолог Ленина: «Так рабочим прямо и надо сказать: на земле ли, в космосе, но мы покончим с болезнями и со смертью тоже; тот, кто достоин, будет жить вечно, и не с этой сусальной ангельской анемией, а по-настоящему, по-человечески, с женщинами, с вином, с хорошим обедом - словом, со всеми радостями плоти» ${ }^{28}$. «Воскрешение всех умерших, убитых и умученных, наступит при коммунизме, когда покойные восстанут из пепла» ${ }^{29}-$ при условии, конечно, что память о них будет досрочно увековечена.

У Шарова в проекте воскрешения советского народа посредством фиксации их воспоминаний принимают активное уча-

${ }^{24}$ Там же, с. 38.

25 А. Беззубцев-Кондаков, Непредсказуемая реальность Владимира Шарова....

${ }^{26}$ Действительно, в произведениях Шарова присутствуют все типичные структуры мышления, свойственные мифу - от нарушения причинно-следственных связей и совмещения разных времён и пространств, до употребления «метафорического слова», что часто отражается на сюжетно-композиционном уровне (нередко автор прибегает к притчам и легендам).

${ }_{27}^{27}$ Там же.

${ }^{28}$ В. Шаров, До и во время..., с. 67.

${ }^{29}$ А. Беззубцев-Кондаков, Непредсказуемая реальность Владимира Шарова.... 
стие, как ни странно, работники НКВД. В романе Воскрешение Лазаря энкавэдэшник по фамилии Спирин утверждает, что архивы Народного комиссариата внутренних дел выполняют функцию сохранения «подробнейшей топографической карты человека» ${ }^{\circ}$, то есть, миллионов папок следственных дел, которые содержат подробнейшие детали о жизнях советских граждан, обретённые во время допросов и расследований. Чекист объясняет, что НКВД лишь «временно» избавлялся от тех, кто мешал основной, центральной задаче, поставленной перед большевистской партией, - всеобщему воскрешению, чтобы, осуществив этот проект, вернуть гражданам жизнь. На вопрос: «[...] почему нельзя было, арестовав, не мучить их, не издеваться, а сразу расстрелять?», Спирин отвечает:

Мы пытали не потому, что садисты, не потому, что нам нравилось смотреть, как они в собственной крови и блевотине ползают у наших ног, и не для того, чтобы растоптать, требовали мы от подследственного буквально вывернуть себя наизнанку, рассказать, кто, где, почему; заставляли заложить и предать всех, с кем он когда-либо жил, был дружен или вместе работал, и лишь потом позволяли ему умереть. Нет, прежде чем дать уйти, мы обязаны были до последней капли узнать его подноготную, обязаны были знать арестованного лучше, чем его знала мать и нянька, жена и любовница. Без этого мы никогда не сумеем воскресить казнённых такими, какими они были ${ }^{31}$.

В этом и состоит «неожиданная реальность», по словам Беззубца-Кондакова, Владимира Шарова. Его творчество, получившее отрицательные оценки некоторых литературных критиков ${ }^{32}$

${ }^{30}$ В. Шаров, Воскрешение Лазаря..., с. 290.

${ }^{31}$ Там же.

$3^{2}$ Достаточно упомянуть открытое письмо Сор из избы, в котором Сергей Костырко называет До и во время «конъюнктурной литературой [...] обслуживающей достаточно широкий круг так называемого интеллигентного читателя, очень бы желавшего быть „на уровне” современной художественной мысли», а Ирина Роднянская - «литературной симуляцией». См.: С. Костырко, И. Роднянская, Сор из избы, «Новый мир» 1993, № 5, с. 186-189. Другие критики считают творчество Шарова примером «вторичного, утилизирующего, но абсолютно никчемного „неискусства”». См.: А. Пурин, Воспоминания о Евтерпе. Статьи и эссе // Urbi, Литературный альманах, вып. 9, «Звезда», Санкт-Петербург 1996, с. 122; другие ещё - чем-то «загадочным», «запутанным». См.: Е. Белжеларский, Некуда бежать, «Итоги» 2013, № 32, http://www.itogi.ru/arts-kniga/2013/32/192927.html (23.08.2019). По Интернету Шаров известен как «мастер интеллектуальной провокации». См.: Биография Владимира Шарова, «РИА Новости» 2018, https://ria. $\mathrm{ru} / 20180817 / 1526738525 \cdot \mathrm{html}(23.08 .2019)$. 
и неоднозначную реакцию со стороны читателей, не только ориентируется на фантасмагорическую мифологизацию прошлого и настоящего ${ }^{33}$, но и ставит себе целью объяснить религиозные корни большевистской революции, разрабатывая весьма альтернативную концепцию русской религиозности. Отсюда систематическое для шаровских произведений приравнивание теории большевизма к православной религии, в котором характерное для эстетики постмодернизма столкновение сфер sacrum и profanum неминуемо.

В романе Репетиции ${ }^{34}$ описание спасательной миссии энкавэдэшников обогащается новыми деталями: по мнению государственного следователя по фамилии Челноков, чекисты должны в первую очередь воскресить писателей, которым предстоит прославлять в своих произведениях коммунистический рай на Земле, затем повергнуть в небытие врагов революции, которые

должны быть искоренены, и память о них тоже. Эти люди должны будут исчезнуть навсегда, навечно, исчезнуть так, чтобы о них ничего не знали ни дети их, ни внуки, даже что они вообще были. От них ничего не должно остаться, они должны сгинуть, как сгинули и растворились среди других народов бесписьменные печенеги и половцы ${ }^{35}$.

Однако, продолжает Челноков, чекисты в конце концов проявят милосердие, спасая и этих обречённых: «Все те, кто пройдет через наши руки, спасутся. Мы воскресим и многих из уже погибших. Год назад я добился папок для новых дел. На них написано: „Хранить вечно” [...] Так они обречены, а эта надпись сохранит их, не даст сгинуть» ${ }^{36}$. В Воскрешении Лазаря Николай Аксентьевич Костюченко, член коллегии ОГПУ, утверждает, что представители власти должны воскресить советский народ «по кусочкам, по фрагментам, как сыщик восстанавливает картину преступления» ${ }^{37}$, но называет эту память «палаческой»: только чекистам дано выбирать то, какие детали о жизни своих жертв сохранить, чтобы вырвать их из небытия.

${ }_{33}$ Наум Лейдерман и Марк Липовецкий определяют прозу Шарова как «постмодернистский квазиисторизм» или «историческую фантасмагорию». См.: Н. Лейдерман, М. Липовецкий, Современная русская литература: 19501990-е годы, т. 2: 1968-1990, Издательский центр «Академия», Москва 2003, c. $484-487$.

34 Роман Репетиции впервые вышел в 1992 г. на страницах журнала «Нева».

${ }_{35}$ В. Шаров, Репетиции, Лимбус Пресс, Санкт-Петербург 2003, с. 25.

${ }^{36}$ Там же.

37 В. Шаров, Воскрешение Лазаря..., с. 82. 
В шаровском неомифе энкавэдэшники не только становятся хранителями воспоминаний (в романе Будъте как дети рассказчик, решив справиться со сложной задачей собрать, записать и увековечить устные предания самодийского народа энцов, неслучайно говорит: «[...] чтобы это повязать на бумаге, нужен чекист из тех, кто готовил процессы тридцатых годов» $\left.{ }^{8}\right)$, но и сопоставляются в интересных параллелизмах с библейскими текстами: НКВД, например, играя решительную роль в осуществлении всеобщего воскрешения советских граждан, является своего рода советским Страшным судом; слова чекиста Челнокова («Все те, кто пройдет через наши руки, спасутся») созвучны с речью Христа о себе как о добром пастыре из Евангелия от Иоанна ( «Я есмь дверь: кто войдет Мною, тот спасется» ${ }^{39}$ ); а утопическое построение коммунистического общества постоянно сравнивается с библейским раем на Земле.

В произведениях Владимира Шарова главной функцией человеческой памяти является способность «сохранить» воспоминания индивидуума посредством их запечатления в текстовой форме. Бумажный дневник, в котором сохраняются в хронологическом порядке все мельчайшие детали из жизненного опыта индивидуума, а также протоколы допросов, находящиеся в архивах НКВД, становятся самыми важными хранилищами памяти, благодаря которым герои, населяющие шаровскую вселенную, обретают возможность не только овеществить память, но и «возвращаться назад» - пережить всё заново, продолжать жизнь в собственных воспоминаниях. В этом ракурсе возможность зафиксировать материально жизненный опыт человека становится у Шарова стратегией обретения «практического» бессмертия, то есть, продления собственного существования в социокультурном пространстве, а вопрос памяти принимает эсхатологический размах: память отождествляется с вечным существованием, отрицающим смерть (бессмертием), а забвение - с полным, бесследным исчезновением индивидуума (смертью).

${ }_{38}^{8}$ В. Шаров, Будъте как дети, Издательство АСТ: Редакция Елены Шубиной, Москва 2017, с. 19.

${ }^{39}$ Иоанн, 10:9. 


\section{ӘСХАТОЛОГИЧЕСКИЙ ХАРАКТЕР ПАМЯТИ...}

\section{REFERENCES}

Ashcheulova, Irina. "Problema poiska, sokhraneniya i realizatsii tsennostey kak problema svyazi pokoleniy v romane V. Sharova 'Voskresheniye Lazarya'." Russkaya literatura $v$ XX veke: imena, problemy, kul'turnyy dialog, no. 9: "Ottsy" $i$ “deti” $v$ russkoy literature XX veka, Tomsk 2008 [Ащеулова, Ирина. "Проблема поиска, сохранения и реализации ценностей как проблема связи поколений в романе В. Шарова 'Воскрешение Лазаря'.” Русская литература в ХХ веке: имена, проблемы, культурный диалог, по. 9: “Отцы” и "дети" в русской литературе XX века, Томск 2008].

Bezzubtsev-Kondakov, Aleksandr. "Nepredskazuyemaya real'nost' Vladimira Sharova." Severnaya Avrora 2010, no. 11. 23.08.2019 <http://reading-hall. ru/publication.php?id=3704> [Беззубцев-Кондаков, Александр. “Непредсказуемая реальность Владимира Шарова.” Северная Аврора 2010, no. 11. 23.08.2019 <http://reading-hall.ru/publication.php?id=3704>].

Belzhelarskiy, Yevgeniy. "Nekuda bezhat'." Itogi 2013, no. 32. 23.08.2019<http:// www.itogi.ru/arts-kniga/2013/32/192927.html> [Белжеларский, Евгений. "Некуда бежать." Итоги 2013, no. 32. 23.08.2019 <http://www.itogi.ru/artskniga/2013/32/192927.html>].

Bondar, Aleksandr, Psikhologiya pamyati. Uchebnoye posobiye dlya bakalavriata i magistratury. Red. Aleksandr Kasatov. Yekaterinburg: Izdatel'stvo Ural'skogo universiteta, 2018 [Бондар, Александр, Психология памяти. Учебное пособие для бакалавриата и магистратуры. Ред. Александр Касатов. Екатеринбург: Издательство Уральского университета, 2018].

Kostyrko, Sergey, and Rodnyanskaya, Irina. "Sor iz izby." Novyy mir 1993, no. 5. 186-189 [Костырко, Сергей, Роднянская, Ирина. “Сор из избы.” Новый мир 1993, no. 5. 186-189].

Leyderman, Naum, and Lipovetskiy, Mark. Sovremennaya russkaya literatura: 1950-199o-ye gody, t. 2: 1968-199o. Moskva: Izdatel'skiy tsentr "Akademiya", 2003 [Лейдерман, Наум, Липовецкий, Марк. Современная русская литеpaтура: 1950-1990-е годы, т. 2: 1968-199о. Москва: Издательский центр “Академия", 2003].

Purin, Aleksey. "Vospominaniya o Yevterpe. Stat'i i esse." Urbi, Literaturnyy al'manakh, no. 9. Sankt-Peterburg: Zvezda, 1996 [Пурин, Алексей. "Воспоминания о Евтерпе. Статьи и эссе.” Urbi, Литературный альманах, nо. 9. Санкт-Петербург: Звезда, 1996].

Stepanova, Mariya. Pamyati pamyati. Romans. Moskva: Novoye izdatel'stvo, 2018 [Степанова, Мария. Памяти памяти. Романс. Москва: Новое издательство, 2018].

Sharov, Vladimir. Bud'te kak deti. Moskva: Izdatel'stvo AST: Redaktsiya Yeleny Shubinoy, 2017 [Шаров, Владимир. Будьте как дети. Москва: Издательство ACT: Редакция Елены Шубиной, 2017].

Sharov, Vladimir. Vozvrashcheniye $v$ Yegipet. Moskva: Izdatel'stvo AST: Redaktsiya Yeleny Shubinoy, 2015 [Шаров, Владимир. Возвращение в Египет. Москва: Издательство АСТ: Редакция Елены Шубиной, 2015].

Sharov, Vladimir.Voskresheniye Lazarya. Moskva: Vagrius, 2003 [Шаров, Владимир. Воскрешение Лазаря. Москва: Вагриус, 2003].

Sharov, Vladimir. Do i vo vremya. Moskva: Arsisbooks, 2009 [Шаров, Владимир. До и во время. Москва: ArsisBooks, 2009]. 


\section{FILIPPO CAMAGNI}

Sharov, Vladimir. Repetitsii. Sankt-Peterburg: Limbus Press, 2003 [Шаров, Владимир. Репетиции. Санкт-Петербург: Лимбус Пресс, 2003].

Sharov, Vladimir. Staraya devochka. Moskva: Nash dom - L’Age d'Homme, 2009 [Шаров, Владимир. Старая девочка. Москва: Наш дом - L’Age d'Homme, 2009].

Sheyko-Malen'kikh, Irina. "Problemy poetiki prozy Vladimira Sharova." Izvestiya RGPU im. A. I. Gertsena 2006, no. 19. 84-87 [Шейко-Маленьких, Ирина. “Проблемы поэтики прозы Владимира Шарова.” Известия РГПУ им. А.И.Герцена 2006, no. 19. 84-87]. 